\title{
Electrochemical Sensors and Determination for Heavy Metal by Rotating Disk Platinum Electrode and Chronoamperometric Method
}

\author{
Ahmad Khalaf Alkhawaldeh ${ }^{1}$ \\ Department of Pharmaceutical Chemistry; College of Pharmacy, Jerash University, \\ Jordan.
}

\begin{abstract}
Pollution by heavy metals is one of the most severe environmental issues that threaten global sustainability. This review presents a recent advance in electrochemical sensors for heavy metal detection Rotating Disk Platinum Electrode are discussed. This study on the production of a modern natural water electrochemical antimony (II) and cupper (II) test include the use of platinum electrode. Antimony and cupper were pre-concentrated on the modified electrode surface and adsorbed to the surface, oxidizing at $\mathrm{E}=540 \mathrm{mV}$ and $\mathrm{E}=85 \mathrm{mV}$, respectively. After 20 min of accumulation, time the best-defined anodic peak was obtained of surface. The precision was tested by carrying out chronoamperometric measurements at a concentration of $\mathrm{Sb}^{+2}$ and $\mathrm{Cu}^{+2} 8.5 \times 10^{-8} \mathrm{M}$ and $9.5 \times 10^{-7} \mathrm{M}$, respectively.
\end{abstract}

Keywords: Heavy Metal, Chronoamperometric, Platinum Electrode, Rotating Disk

\section{Introduction}

Pollution from heavy metals challenges environmentally friendly structures and poses a great global sustainability challenge. Heavy metals are the major contributors to water contamination, resulting in a severe human tragedy. As cities are expanded and industrialization is developed, waste sewage from life and industry are drained into the water environment. Heavy metals, bio-concentration, food chains, and through potable water, are severely threatening human health (Shen. et al., 2017).

Electrochemical sensors have gained attention in recent years in the area of atmosphere control and heavy metal detection. It has several advantages, online analysis, and ease of use, including simple equipment, high sensitivity and on-site testing. The TLFC towing distribution was simulated using the Finite Element Method (FEM) and electrical form and configuration were also optimized (Chmayssem, and Hauchard, 2017).

All three electrodes were manufactured on the basis of carbon nanotube (CNT) thread in an electrochemical cell. As the representative method of this analysis, $\mathrm{Pb}^{2+}, \mathrm{Hg}^{2+}$ and $\mathrm{Cu}^{2+}$ were used. The detection limit for $\mathrm{Pb}^{2+}, \mathrm{Hg}^{2+}$ and $\mathrm{Cu}^{2+}$, estimated on the basis of this method, with $120 \mathrm{~s}$ of deposition time is $1.05,0.53$, and $0.57 \mathrm{nmol}, \mathrm{L}^{-1}$, respectively. This study shows that a low-costs copper $(\mathrm{Cu})$ electrochemical sensor is used to measure lead $(\mathrm{Pb})$ in surface water samples. Our copper-based sensor has a low-cost material copper electrode that provides simple manufacturing and competitive electric chemistry detection performance (Alkhawaldeh, and Alkhawaldeh, 2020).

For both metal ions of $120 \mathrm{~s}$ deposition time and a potential deposition of $-1.2 \mathrm{~V}$ in $\mathrm{pH} 4.5$ acetate buffer solution, the lineal range of a Bismuth film electrode was from $\mu \mathrm{g} \mathrm{L}^{-1}$ to $100.0 \mu \mathrm{g} \mathrm{L}^{-1}$. The electrode was also applied in soil sample extracts to determine cadmium and lead. While the electrochemistry provides a simple method of metal detection on a micro scale, it is difficult or expensive to produce traditional carbon, gold (Au) or platinum (Pt) electrodes that prohibit the widespread use. Zinc detection (calculated) $140 \mathrm{~nm}(9.0 \mathrm{ppb})$, and a sensitivity above $1 \mu \mathrm{A}$ $\mu \mathrm{M}^{-1}$ in the acetate buffer were shown by anodic stripping voltammetry using our new copper-based sensors (Alkhawaldeh et al, 2020).

Thereby, a micro-sensor $(\mu \mathrm{CS})$ for trace heavy metal detection of highly sensitive, robust and cost-effective electro-chemical carbon-based sensors is provided. Detection limits down to $1.8 \mu \mathrm{g} \mathrm{L}^{-1}$ for $\mathrm{Pb}^{2+}$ and $1.2 \mu \mathrm{g} \mathrm{L}^{-1}$ for $\mathrm{Cd}^{2+}$ can be achieved over the $\mu \mathrm{CS}$ (Shen et al, 2017).

The chronopotentiometry of derivative stripping has been used to determine reliably, sensibly and quickly $\mathrm{Pb}$, $\mathrm{Zn}, \mathrm{Cd}, \mathrm{Cu}, \mathrm{Mn}, \mathrm{Ni}$, and $\mathrm{Se}$ in hydrochloric extracts from the $\mathrm{CEO}$; detection limits of $<1 \mu \mathrm{g} \mathrm{kg}^{-1}$ were obtained for all studied metal under optimal electrochemical conditions. The results showed that Mn was the largest metal in all the CEOs, followed by $\mathrm{Zn}, \mathrm{Se}, \mathrm{Cu}, \mathrm{Pb}$ and $\mathrm{Ni}$. The concentrations of $\mathrm{Cd}$ were often smaller than the maximum $(0.6 \mu \mathrm{g} \mathrm{kg}$ 1). 
The cost-efficient technology which could make for a three dimensional combination of microfluidic colorimeter and electrochemical paper-based analytical devices (mPAD) accessible to the developing world as well as to the developed world (Hourani and Alkawaldeh, 2016).

The exfoliated $\mathrm{ZrP}$ is shown to be the best possible adsorption to $\mathrm{Pb}$ (II) between all heavy metal ions, resulting in selective detection. The nanocrystals of octahedral $\mathrm{Fe} 3 \mathrm{O} 4$ exhibit better electric sensor output in comparison with cubic heavy metal ions investigated such as $\mathrm{Zn}$ (II), $\mathrm{Pb}$ (II), Cd (II), $\mathrm{Hg}$ (II) and Cu (II). Finally, the potential application of $\mathrm{Fe}_{3} \mathrm{O}_{4}$ nanocrystals in drinking water to electrochemical detection for As (III) is demonstrated as a test to find a disposable platform totally free of any noble metals. We have assembled a two-dimensional silica/gold spherical cavity microelectrode array using the monolayer template of self-assembly Polystyrene microspheres and the pulse electrodeposition method to test the performance of this method using the square wave pulse voltammetry method (Altweiq and Alkhawaldeh, 2019).

The array has a greater capacity to resist $\mathrm{Cu}$ (II) interference. Hydroxyapatite Nano-sized has been developed and used for the detection of $\mathrm{Pb}^{2+}$ with a width from $20-25 \mathrm{~nm}$ and length of $50-100 \mathrm{~nm}$ as a special 3D network structure with high adsorbent capability towards $\mathrm{Pb}^{2+}$. Nafion, the polymer for cation exchange, is used as a conductive matrix where NHAP and the ionosphere can be closely bound to the surface of the electrode. With an accumulation time of 10 minutes at the open circuit potential, the electrode has linear range between $5.0 \mathrm{nmol}$ and $0.8 \mu \mathrm{mol}$ (Lin and Huang, 2017).

In real samples a new voltammetric process for measuring a trace lead (II) in a poly (4-vinylpyridine)/mercury film electrode (PVP / MFE), was developed through anodic square wave stripping voltammetry. The principal advantages are good interference resistance, fast identification and good electrode renewal without deoxygenation. Two modification methods were used: $\mathrm{HAuCl}_{4}$ electrochemical reduction and $\mathrm{Au}$ NPs stabilized by citrate electrostatic adsorption. These and other studies have led us to believe that the Au NPs have acted as nuclear deposition plants for $\mathrm{Hg}$ and that the GC or ITO have been superior in mercury removal. In fact, with an ITO surface modified with electrostatically absorbed Au NPs, a remarkable detection limit of $1 \mu \mathrm{m} \cdot \mathrm{L}^{-1}$ of $\mathrm{Hg}$ was achieved (Alshamaileh, et al, 2016).

In the work discussed in this article, an appropriate method for the analytical determination of heavy metal samples has been investigated with the advantage of the use of Platinum/palladium electrodes in conjunction with chronoamperometric and square wave voltammetry.

\section{Experimental}

Both chemicals were listed as reagents and used as approved. By diluting certain chemical compounds into Milli-Q water system), aquatic solutions had been prepared. A water solution path containing the combination of the platinum/palladium electrodes used in this work. The average volume of the sample in the electroanalytical chemical cell was $20 \mathrm{~mL}$ in each trial. This contains platinum/palladium electrodes in glass cell, the reference electrode $\mathrm{Ag} / \mathrm{AgCl}$ : $1 \mathrm{M}$ of $\mathrm{KCl}$ and the platinum counter electrode. Experiment conditions of rotating disk voltammograms: Scan rate is $50 \mathrm{mv} / \mathrm{s}$, rotation speed is $1000 \mathrm{RPM}$, scan range is $-0.2-0.85 \mathrm{~V}$ and peak potential is $0.724 \mathrm{v}$.

\section{Analytical Procedure}

First, the electrode was submerged in a heavy metal solution, which produced a chemical accumulation in an open circuit for iodine monolayer. The electrode was then removed from the electrode, washed in water and relocated to the real voltammetric membrane in which only one electrolyte $\left(0.5 \mathrm{M} \mathrm{H}_{2} \mathrm{SO}_{4}\right)$ was present. Different protocol in sample processing and in room temperature electrochemical experiments were performed.

The same electrochemical systems mentioned above have been used for this calculation before and after immersion in heavy metals containing solution. For AC voltage of 5-10 mV at $0 \mathrm{mV}$ the frequencies from $100 \mathrm{KHz}$ to $10 \mathrm{MHz}$ can now be calculated. After 30 minutes of exposure, computer programs automatically test measurements made at rest potentials. Experiments have been carried out using the open circuit square-wave voltammetric system by deposit of the heavy metal. At the potential -1.0 to $-0.4 \mathrm{~V}$ the accumulated metal was then anodized with a phase potential of $25 \mathrm{mV} ; 5 \mathrm{mV}$ amplitude, $5 \mathrm{sec}$ amplitude and $1 \mathrm{mV} / \mathrm{s}$ scan rate.

\section{Results and Discussion}


Figure 1 indicates the platinum electrode concentration of Antimony (II). With cyclic Voltammetry (CV), the voltammograms were obtained at an appropriate scan rate of $100 \mathrm{mV} \mathrm{s}^{-1}$. Before a pre-concentration phase in Sb (II) solution, the base curve, showing no point, was obtained. As shown in Figure 2, after the pre-concentration phase the peak current revealed that the Sb (II) had been removed from the bulk solution by platinum electrode at different time immersion.

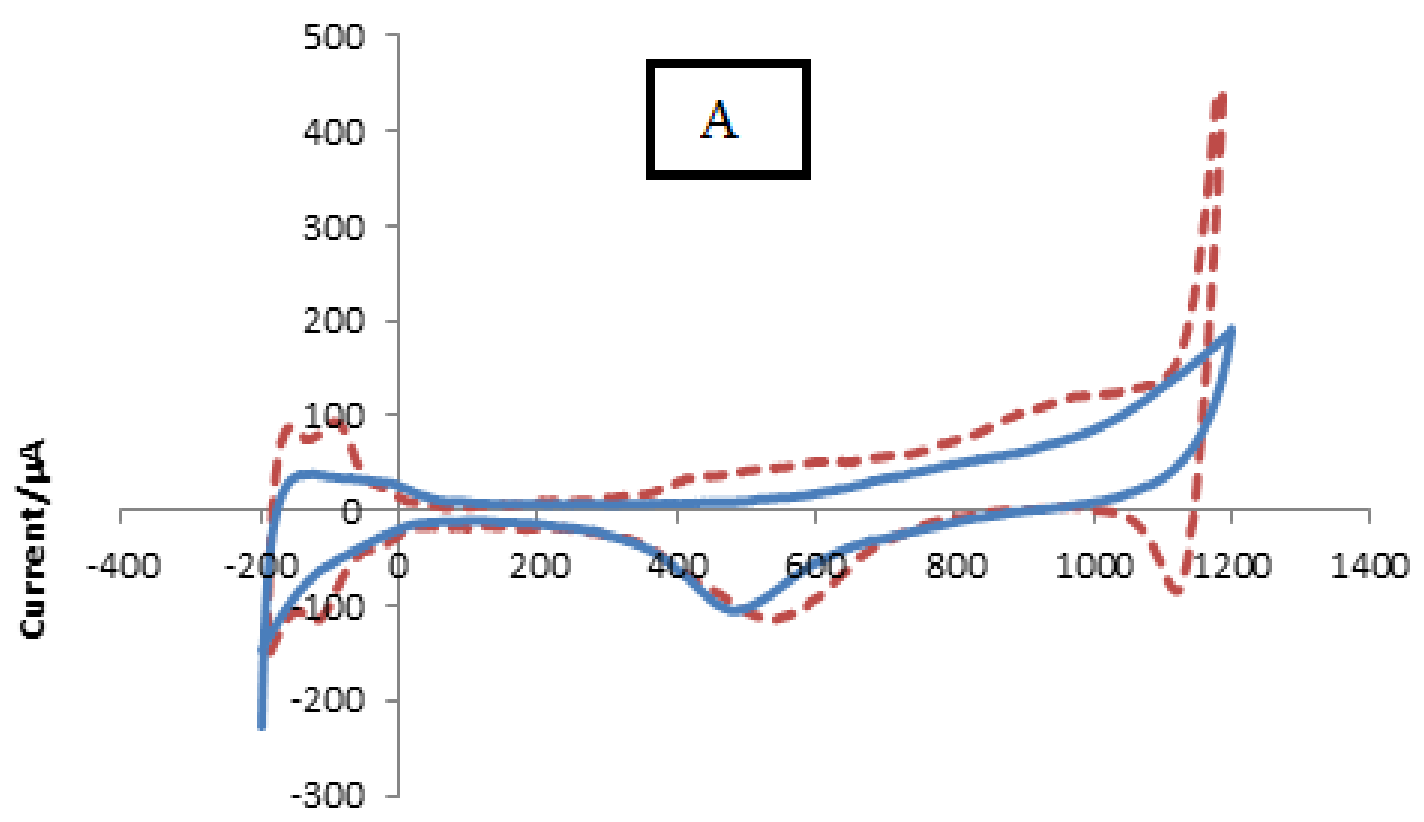

Potential / V vs Ag/Agcl/[Cl- $]=0.1 \mathrm{M}$

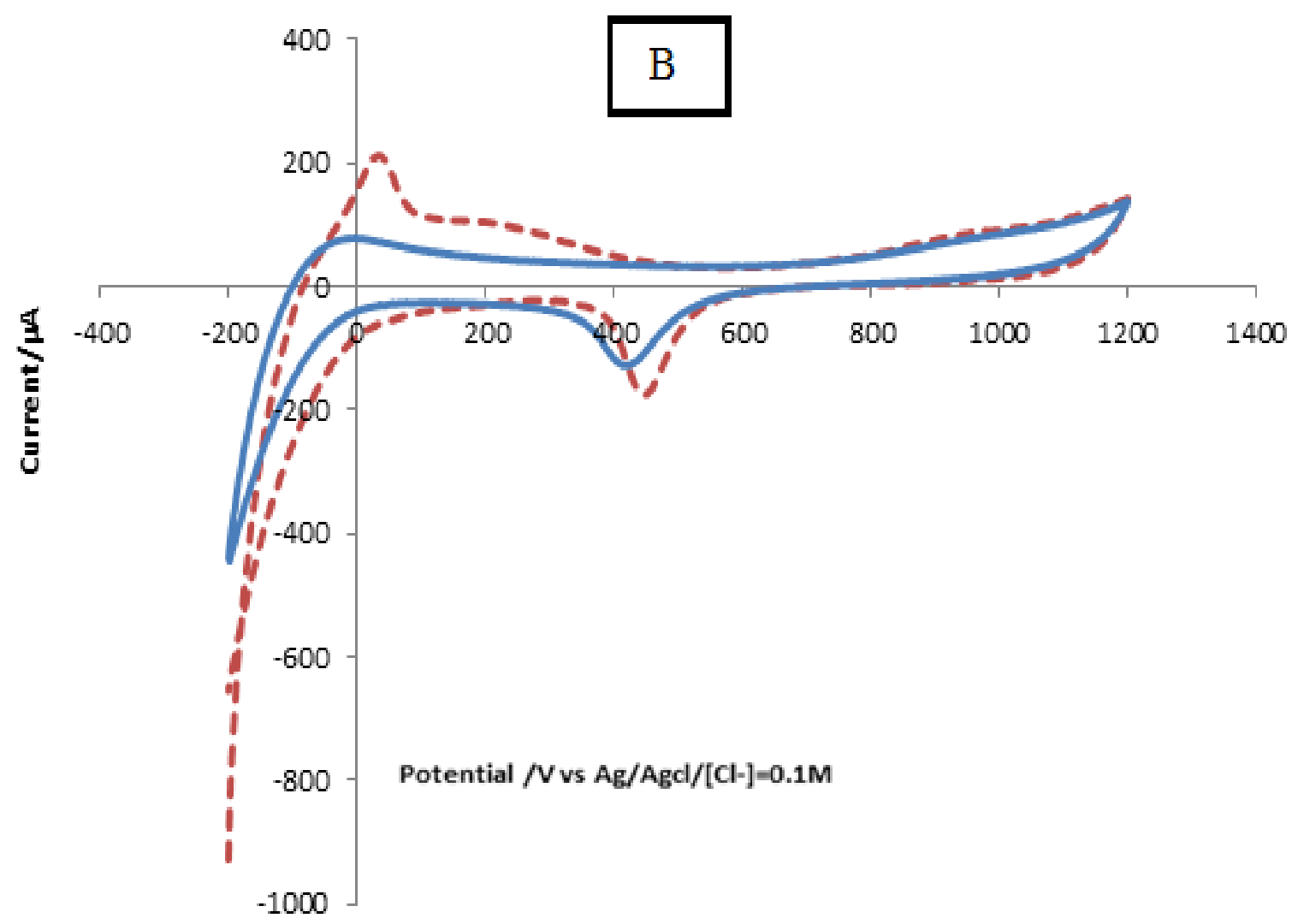




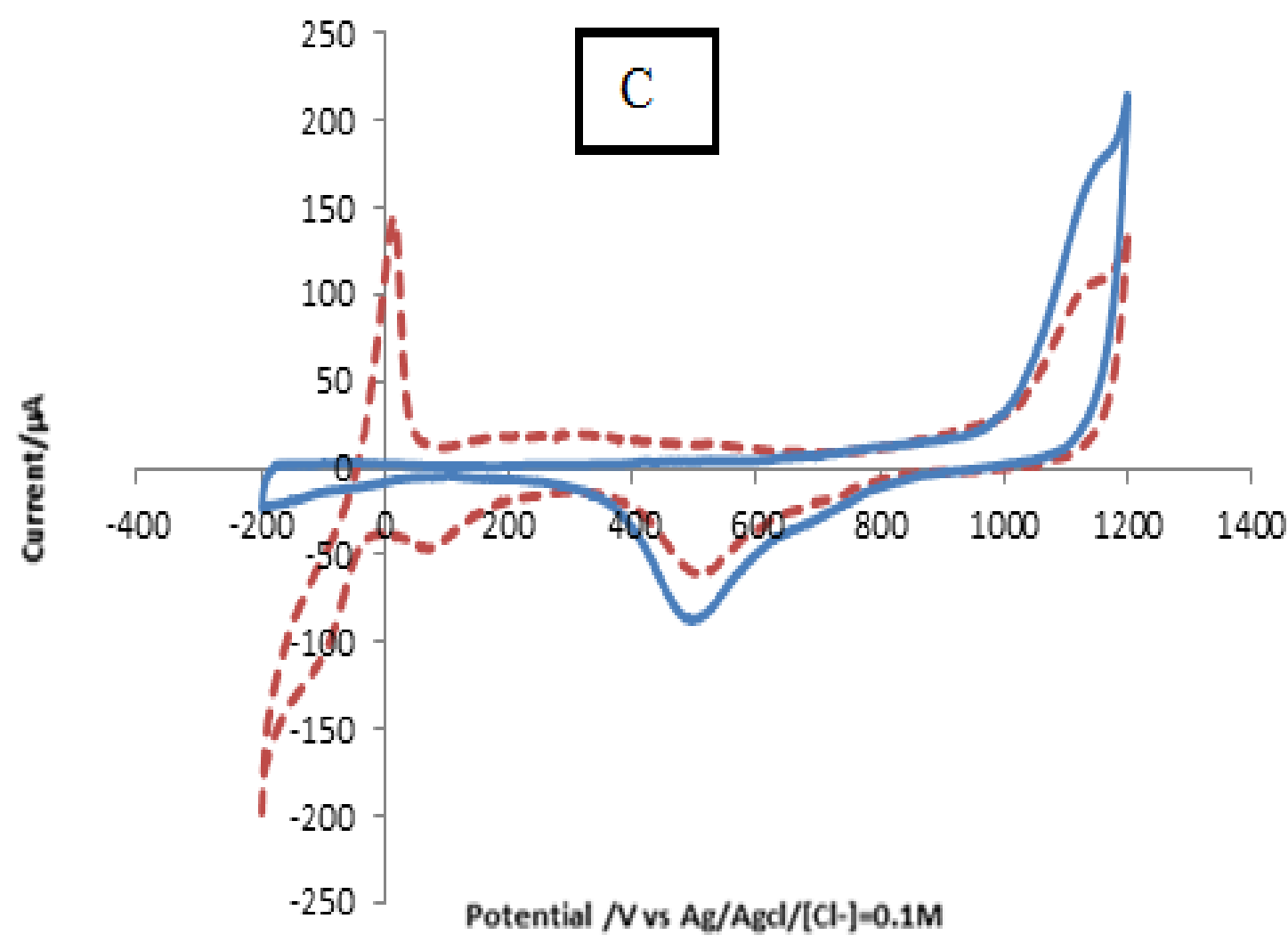

Figure 1. Cyclic voltammograms of platinum electrode before and after incubation with Antimony (II). The scan rate was $100 \mathrm{mV} \mathrm{s}-1$. (A) $[\mathrm{Sb}(\mathrm{II})]=3 \times 10^{-4} \mathrm{M}$ and (B) $[\mathrm{Cu}(\mathrm{II})]=5 \times 10^{-3} \mathrm{M}(\mathrm{C})[\mathrm{I}]=4 \times 10^{-2} \mathrm{M}$.

Figure 1 displays the rotating disk platinum electrode impedance diagram in $3 \mathrm{X}^{-4} 0^{-4} \mathrm{M}$ of Antimony and $5 \times 10^{-3} \mathrm{M}$ of cupper is solution, prior to and after pre-concentration phase. The data demonstrate explicitly that when the Pt is subjected to antimony (II), its capacitance at the interface is increased. In the event of adsorption on the electrode surface, this finding is in line with the literature (Alkhawaldeh et al, 2020). As part of an optimized process that results in electrolytic reduction of the heavy metal in the changed coating, we offer empirical evidence for the Sb (II) ad absorption on the surface. The observed decrease of the resistance to charge transfer often results in the conductivities of the additive electrode that can be clarified with the inclusion of Antimony on the surface of the electrode.

The layer powder on platinum surfaces was analyzed by cyclic voltammetry on the electrode before and after the pre-concentration stage in antimony solution. As seen in Figure 2, Sb (II) and Cu (II) has been observed with a pair of stable and well-defined redox peaks. This findings suggest that after pre-concentration in the antimony solution Sb (II) and $\mathrm{Cu}$ (II) are present in or / and appetite coating platinum electrodes. The result reveals that the platinum electrode surface is an important element in the $\mathrm{Sb}$ (II) and $\mathrm{Cu}$ (II) accumulation cycle, indicating the systemic manipulation of anodic surface processes by cyclic voltammetry with some critical advantages.

The Platinum electrode immersion time in $\mathrm{Sb}$ (II) and $\mathrm{Cu}$ (II) solution had a significant effect on the surface state and the impedance of the electron transmission. It can be shown that with the introduction of the adsorption time, the diameter of the semicircle has decreased to greater frequencies. There was no dramatic improvement at the interface electron transmission resistance, suggesting that $\mathrm{Sb}$ (II) and $\mathrm{Cu}$ (II) adsorption exceeded saturation point, when the soaking time in the antimony solution was more than 20 min (in Figure 2).

The tests of these antimony ultra-traces are shown to be extremely suitable in water samples where a maximum suggested residual stipulation is $10 \mu \mathrm{g} / \mathrm{kg}$ suggesting that antimony (II) can be studied in natural water samples (Almatarneh et al., 2019). 


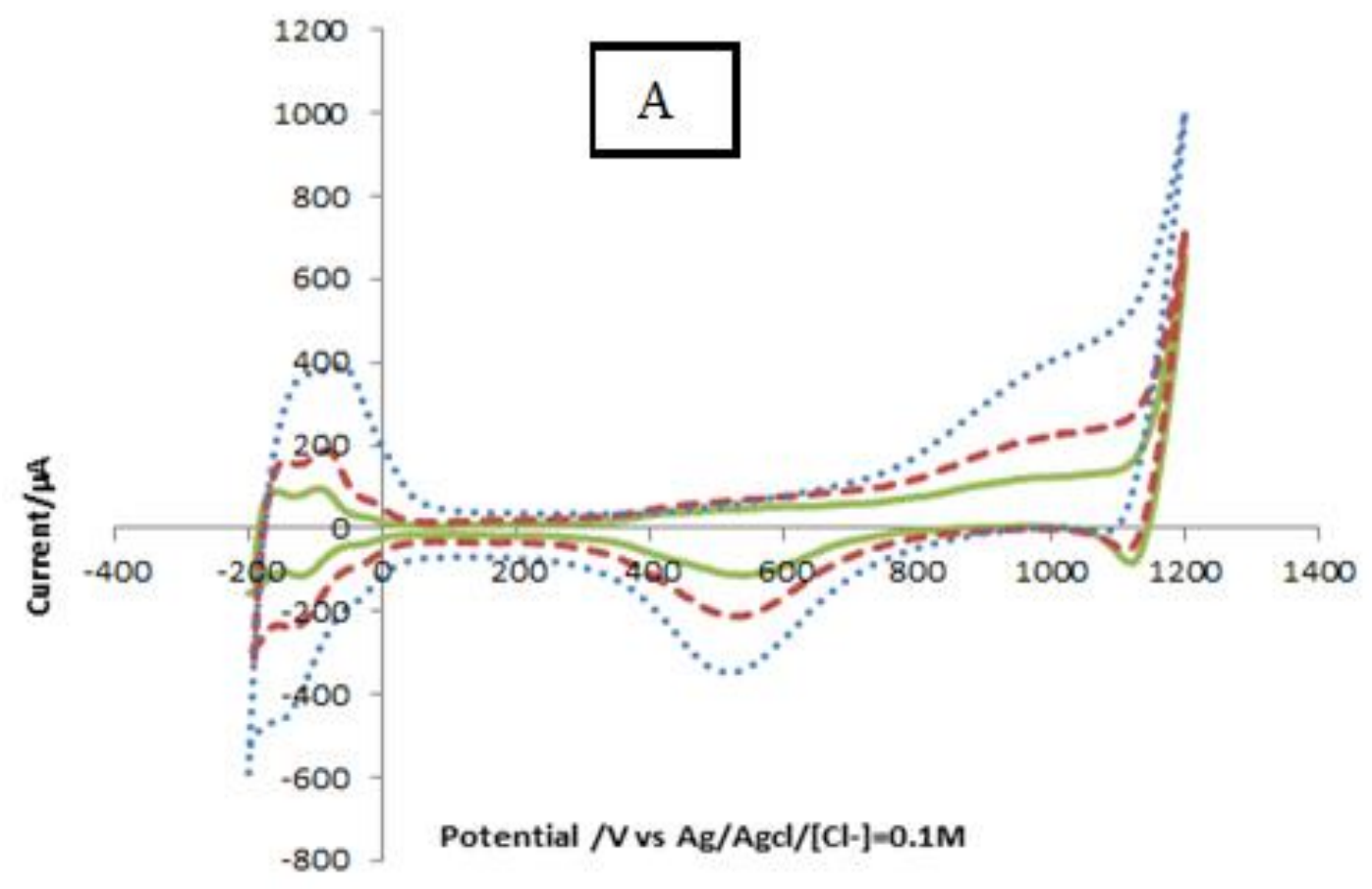



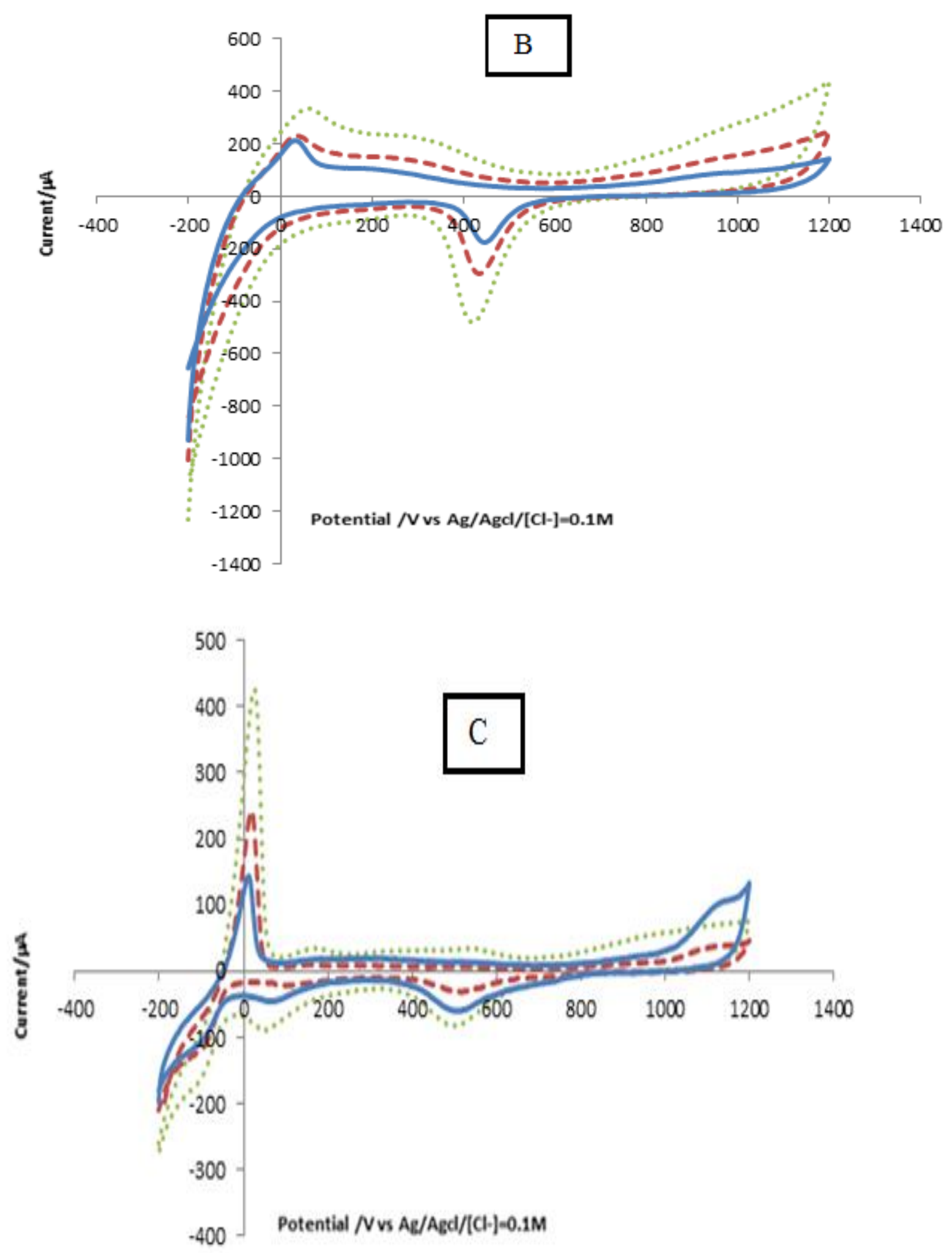

Figure 2. Cyclic voltammograms of platinum electrode with Antimony (II) at different immersion time, (the immersion time is 10,15 , and $20 \mathrm{~min}$ ). During scan rate $100 \mathrm{mV} \mathrm{s}^{-1}$; concentration of (A) $[\mathrm{Sb}$ (II) $]=3 \times 10^{-4} \mathrm{M}$ and (B) $[\mathrm{Cu}(\mathrm{II})]=5 \times 10^{-3} \mathrm{M}$ and $(\mathrm{C})[\mathrm{I}]=4 \times 10^{-2} \mathrm{M}$.

The layer powder on platinum surfaces was analyzed by cyclic voltammetry on the electrode before and after the pre-concentration stage in antimony solution (Figure 3). As seen in Figure 4, Sb (II) has been observed with a pair 
of stable and well-defined redox peaks. This findings suggest that after pre-concentration in the antimony solution $\mathrm{Sb}$ (II) is present in or / and appetite coating platinum electrodes. The result reveals that the nanoparticle is an important element in the $\mathrm{Sb}$ (II) accumulation cycle on the platinum electrode surface, indicating the systemic manipulation of anodic surface processes by square wave voltammetry with some critical advantages.

The tests of these antimony ultra-traces are shown to be extremely suitable in water samples where a maximum suggested residual stipulation is $10 \mu \mathrm{g} / \mathrm{kg}$ suggesting that antimony (II) can be studied in natural water samples. The lower concentration detection is $0.4 \mathrm{ppm}$ and higher concentration of metal is $100 \mathrm{ppm}$.

The test plot produced in the above conditions (20 min deposition time) as shown in Figure 3. Linear reaction to a sensitiveness (path) of $0,0301 \mu \mathrm{A}$ per antimony and cupper $1 \mu \mathrm{mol}(\mathrm{R} 2=0,991)$ was reached in platinum nanoelectrodes to $20 \mathrm{M}$. The lower detection limit is 3 and the quantitative limit is 4 , which were five times the normal variance of the results obtained for a white person, were $8.5 \times 10^{-8} \mathrm{M}$ and $9.5 \times 10^{-7} \mathrm{M}$ respectively.

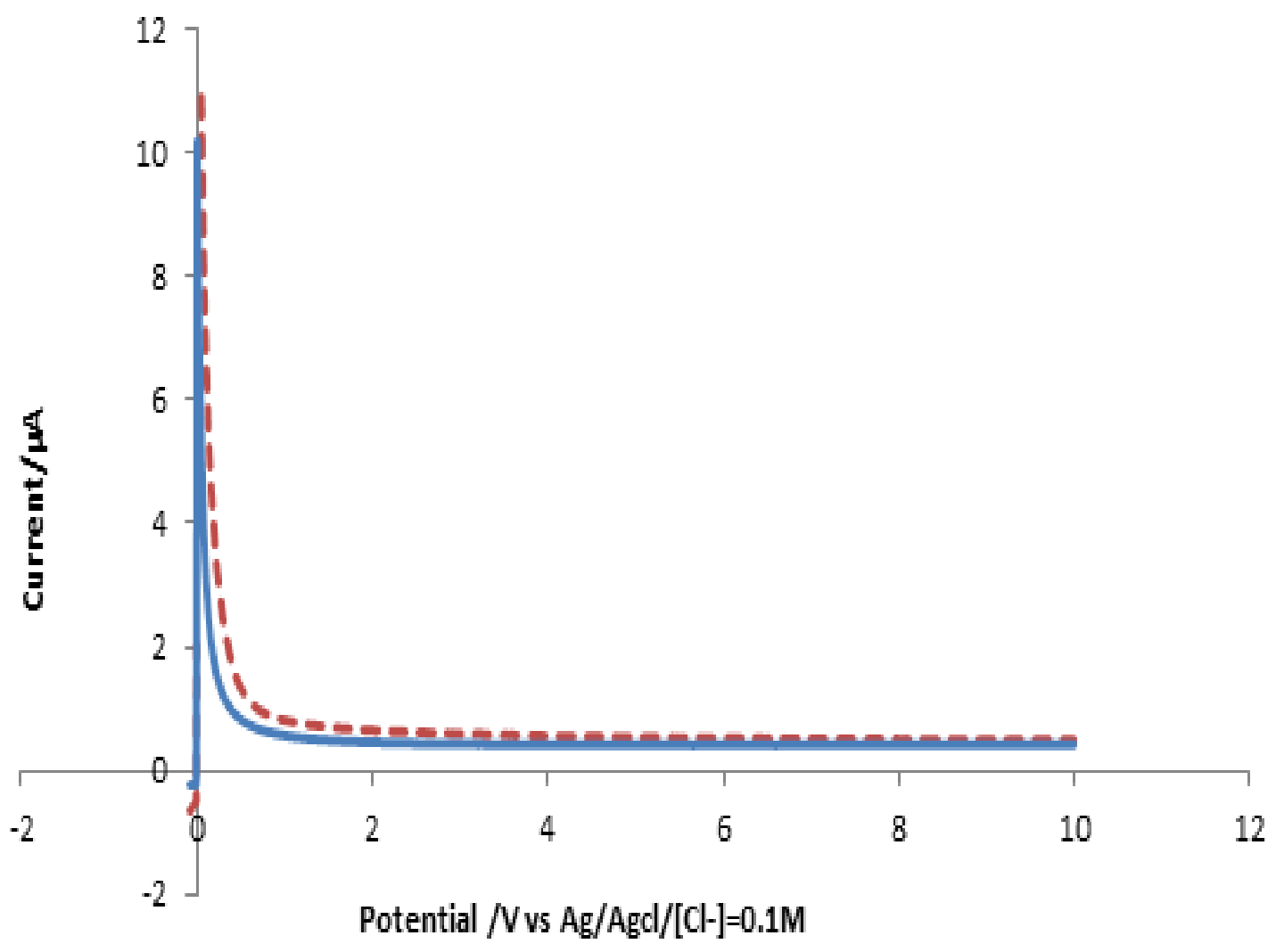




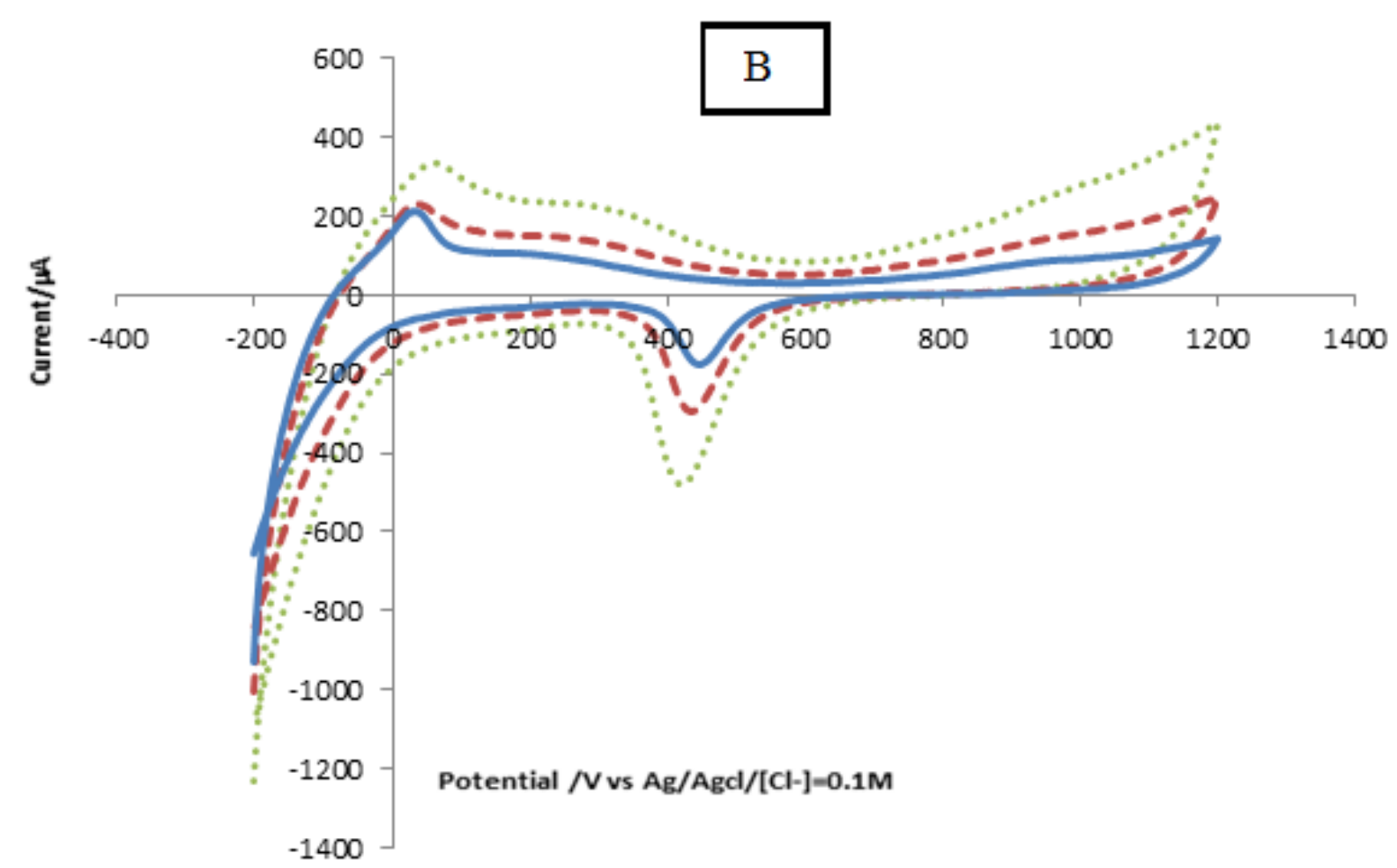

Figure 3. CA of antimony and cupper calibration plot generated using the optimum conditions determined at $\mathrm{pH} 6.5$ and 0.2 mol. $1^{-1}$ Antimony nitrate.

The method for electroplating the electrode surface with bismuth is critical to obtaining satisfactory performances. Three methods exist to realize a bismuth deposit. The first method, ex situ plating, consists of electroplating the bismuth film before transferring the electrode into the sample solution for analysis. The plating conditions are variable but acidic media are recommended as bismuth ions are easily hydrolyzed as high $\mathrm{pH}$. Plating solutions containing 5-200 $\mathrm{mg} \cdot \mathrm{L}^{-1} \mathrm{Sb}$ (II) are used with

\section{Conclusions}

Electrochemical sensors have a number of advantages as surveillance tools: they have a high sensitivity, good stability, low costs, and simple operation. It is used widely to track emissions, life sciences, food and clinical diagnosis. It was shown that with cyclic and square wave voltammetry, one well-defined anode peak could be achieved at a power of $0.74 \mathrm{~V}$ versus $\mathrm{Ag} / \mathrm{AgCl}$. The $\mathrm{Sb}$ oxidation accumulated on platinum nanoelectrode takes place. Antimony (II) detection limit of $8.8510^{-8} \mathrm{~mol} \mathrm{~L}^{-1}$ was much higher than those mentioned in the literature when experimental conditions for square wave voltammetry were optimized, and this sensor displayed an broad linear reaction range, good sensitivity, and reproductively. Nevertheless, nanoparticle platinum was the only electro catalyst that would perform the reaction at an acceptable rate. This led to a substantial search for the theoretical electro-catalysis of the square wave voltammetry.

\section{References}

Alkhawaldeh, A. K., M.Krishan, M., Altwaiq, A., Dabaibeh, R. N. (2020). Preparation of Nanostructured/ Microplatinum Surfaces by Application of a Square Wave Potential Regime for Methanol Oxidation. Eurasian Journal of Analytical Chemistry, 15(1), emEJAC-00362.

Alkhawaldeh, A. K., (2020). Analytics of Antimony in Natural Water of Nanoparticle Platinum Electrode by Application Square Wave Voltammetry. International Journal of Multidisciplinary Sciences and Advanced Technology, 1(4): 96-103.

Alkhawaldeh, A. K., (2020). COVID-19: Simultaneous Surveillance Studies and Case Series, Jordan as a Case Study. International Journal of Multidisciplinary Sciences and Advanced Technology. Special Issue 1: Covid-19: 55-62. 
Alkhawaldeh, A. K., (2020). Electrical Conductivity of Natural Volcanic Tuff Mix by Cyclic Voltammetry Method, International Journal of Multidisciplinary Sciences and Advanced Technology, 1(5): 37-44.

Alkhawaldeh, A. K., (2020). Platinum nanoparticle electrode modified iodine used cyclic voltammetry and chronoamperometric for determination of ascorbic acid. Analytical and Bioanalytical Electrochemistry, 12 (6): $780-792$.

Alkhawaldeh, A. K., (2020). Platinum Nanoparticle in Tantalum Electrode for the Electrochemical Analysis of Heavy Metal Ions. International Journal of Intelligent Computing and Technology, 4 (1): 25-35.

Alkhawaldeh, A. K., (2020). Platinum Nanoparticles for the Electrochemical Study of Heavy Metal ions Formed by the Sputtering Deposition of the ion beam Electrode. International Journal of Engineering and Artificial Intelligence. 1(3): 1-8.

Alkhawaldeh, A. K., Alzawahreh, A., Alkhawaldeh, R., (2021). Electrochemical Sensors and Determination for Heavy Metal by Rotating Disk Platinum Electrode and Chronoamperometric Method. International Journal of Engineering and Artificial Intelligence, 2 (1): 17-26.

Alkhawaldeh, A. K., and Alkhawaldeh, R. (2020). Highly Sensitive copper Heavy Metal Analysis on Nanoparticle Platinum and palladium electrode, International Journal of Engineering and Artificial Intelligence. 1(2): 33-39.

Alkhawaldeh, A. K., (2020). Platinum Nanoparticles for the Electrochemical Study of Heavy Metal ions Formed by the Sputtering Deposition of the ion beam Electrode. International Journal of Engineering and Artificial Intelligence. 1(3): 1-8.

Alkhawaldeh, A. K., (2021). Electrochemical Analysis of Heavy metal by Cyclic Voltammetry Method. International Journal of Engineering and Artificial Intelligence, 2 (2): 27-33.

Alkhawaldeh, A. K., (2021). Platinum nanoparticle electrode electrochemical lead (II) determination with square wave voltammetry modified with iodine. AIP Conference Proceedings, 2339 (1): 020221 (2021); https://doi.org/10.1063/5.0045328.

Alkhawaldeh, A. K., Abdel Hadi Al Jafari (2021). Electrochemical Sensors and Determination for silver ion by Cyclic Voltammetry at iodine-coated Platinum nanoparticles electrode. Annals of the Romanian Society for Cell Biology, 25 (6): 20280 - 20291.

Ahmad Khalaf Alkhawaldeh. Technology patterns in Nanochemistry Based on GII Indicator. International Journal of Engineering and Artificial Intelligence, 2 (3). (2021): 28-32.

Ahmad Khalaf Alkhawaldeh. Cyclic voltammogram analysis of the environmental aspects of the use of ferrocenyl carbinols. International Journal of Engineering and Artificial Intelligence, 2 (4). (2021): 7-12. 